\title{
Resource limitation, tolerance, and the future of ecological plant classification
}

\section{Joseph M. Craine ${ }^{1}$, Bettina M. J. Engelbrecht ${ }^{2,3}$, Christopher H. Lusk $^{4}$, Nate G. McDowell ${ }^{5}$ and Hendrik Poorter 6}

1 Division of Biology, Kansas State University, Manhattan, KS, USA

${ }^{2}$ Department of Plant Ecology, University of Bayreuth, Bayreuth, Germany

${ }^{3}$ Smithsonian Tropical Research Institute, Balboa, Ancon, Panama

${ }^{4}$ Department of Biological Sciences, The University of Waikato, Hamilton, New Zealand

${ }^{5}$ Earth and Environmental Sciences Division, Los Alamos National Laboratory, Los Alamos, NM, USA

${ }^{6}$ IBG-2: Plant Sciences, Forschungszentrum Jülich, Jülich, Germany

\section{Edited by:}

Francisco I. Pugnaire, Consejo

Superior de Investigaciones

Cientificas, Spain

Reviewed by:

Heidi Renninger, Boston University, USA

Aurora Gaxiola, Institute of Ecology and Biodiversity, P. Universidad

Católica de Chile, Chile

${ }^{*}$ Correspondence:

Joseph M. Craine, Division of Biology, Kansas State University, Manhattan, KS 66506, USA.

e-mail: jcraine@ksu.edu
Throughout the evolutionary history of plants, drought, shade, and scarcity of nutrients have structured ecosystems and communities globally. Humans have begun to drastically alter the prevalence of these environmental factors with untold consequences for plant communities and ecosystems worldwide. Given limitations in using organ-level traits to predict ecological performance of species, recent advances using tolerances of low resource availability as plant functional traits are revealing the often hidden roles these factors have in structuring communities and are becoming central to classifying plants ecologically. For example, measuring the physiological drought tolerance of plants has increased the predictability of differences among species in their ability to survive drought as well as the distribution of species within and among ecosystems. Quantifying the shade tolerance of species has improved our understanding of local and regional species diversity and how species have sorted within and among regions. As the stresses on ecosystems continue to shift, coordinated studies of whole-plant growth centered on tolerance of low resource availability will be central in predicting future ecosystem functioning and biodiversity. This will require efforts that quantify tolerances for large numbers of species and develop bioinformatic and other techniques for comparing large number of species.

Keywords: plant functional traits, low resource tolerance, resource stress, shade, drought, nutrients

\section{INTRODUCTION}

Drought, shade, and nutrient scarcity limit plant growth worldwide, determine the structure and functioning of terrestrial ecosystems, and are fundamental drivers of plant evolution (Tilman, 1988; Grime, 2001; Valladares and Niinemets, 2008; Craine, 2009; McDowell et al., 2011). Understanding the role these stresses play in structuring ecosystems is critical because different components of environmental change work synergistically to alter the ecological importance of drought, shade, and nutrient scarcity (Field et al., 1992; Figure 1).

The relative importance of drought, shade, and nutrient scarcity in community and ecosystem dynamics are influenced by changes in a number of factors that are undergoing global changes. Each change will uniquely alter the stresses experienced by plants. For example, an increase in precipitation may decrease the importance of drought and increase the importance of shade and nutrient scarcity as water and nutrient availability to plants increases (Stanford and Epstein, 1974; Briggs and Knapp, 1995; Knapp and Smith, 2001). In contrast, since warming increases the rate of nutrient mineralization by microbes (Koch et al., 2007) and increases evapotranspiration (Rind et al., 1990), an increase in temperature would likely decrease the relative importance of nutrient scarcity in many ecosystems while increasing the importance of drought. Many disturbances increase the availability of resources in general and shift plant communities away from species that tolerate the stresses of low resource availability (Wilson and Tilman, 1993; Craine et al., 2001; Grime, 2001) while non-resource stresses, e.g., increased ozone or UV-B, decrease resource demand by plants which would increase the availability of light, water, and nutrients (Searles et al., 2001; Dermody et al., 2006). Ultimately, the changes in vegetation dynamics caused by drought, shade, and nutrient scarcity will be dependent on other current aspects of the ecosystem and global change factors will interact in their ultimate effects. As such, the specific balance of the relative importance of different stresses will be unique to different ecosystems.

With better information about the tolerance of individual species to low availability of resources, changes in species composition can become diagnostic of the relative importance of different global change factors in affecting the terrestrial biosphere. For example, changes in the relative prevalence of drought- vs. shade-tolerant species should be able to be used to discern the relative importance of precipitation vs. nutrient deposition in controlling community composition. Yet, because plant communities are diverse and the interactions among plants, herbivores, microbes, and the abiotic environment is complex, how these changes will ultimately affect the structure and functioning of ecosystems remains poorly understood.

One key to understanding how ecosystems and plant communities will respond to changes in drought, shade, and nutrient 


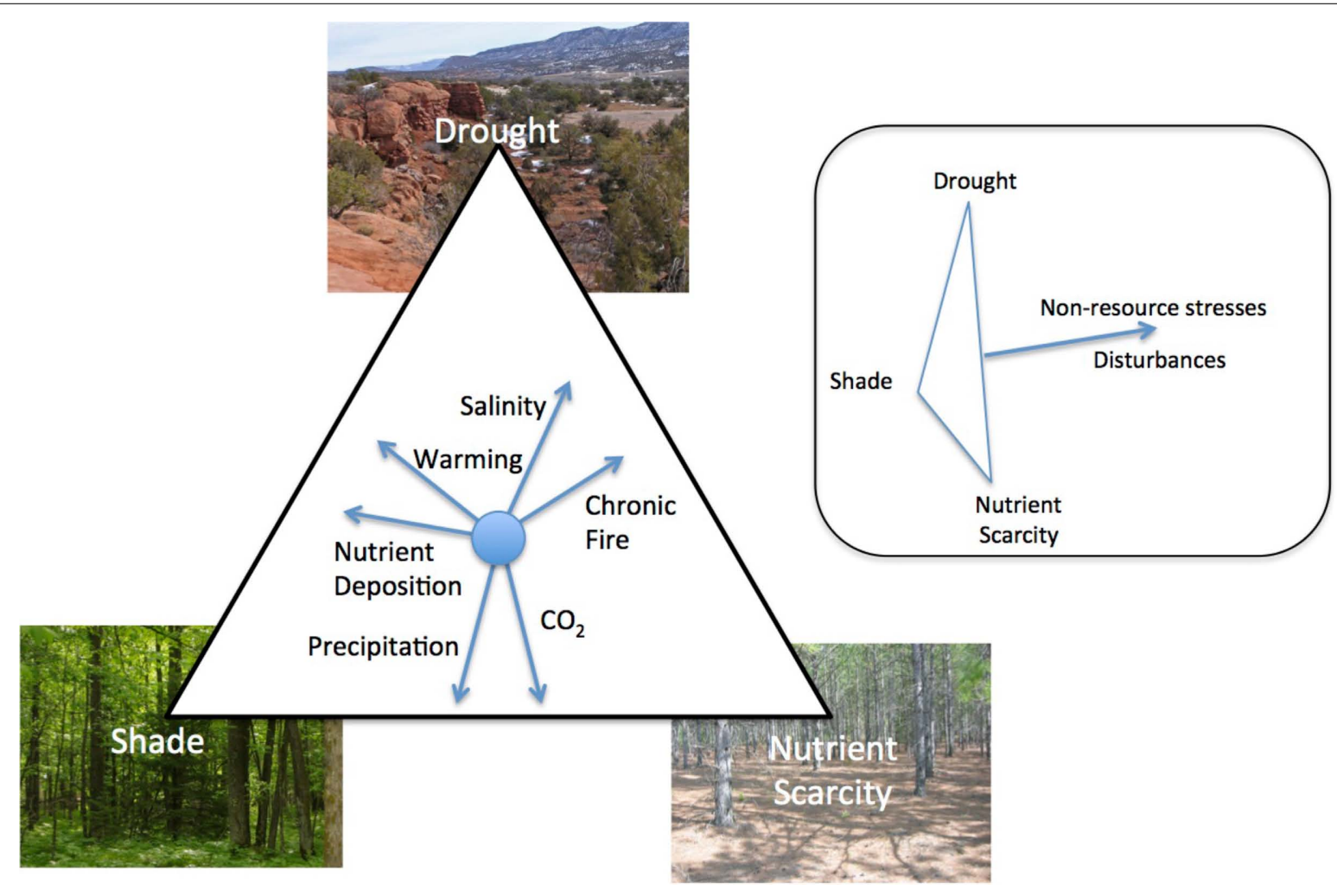

FIGURE 1 |The influence of global change factors on the relative importance of drought, shade, and nutrient scarcity in community and ecosystem dynamics. While some factors alter the importance of the three stresses relative to one another, e.g., nutrient deposition, others like disturbances can reduce total resource stress (inset). Direction of the vector represents the shift in the relative limitation of different resources associated with an increase in the importance of that factor. scarcity is to simplify plant communities by representing species by their key functional traits - evolved characteristics of plants that determine how they interact with their environment. Plant functional trait research dates to the beginnings of ecology as a discipline (Warming, 1909) and today encompasses a broad range of aspects from RNA transcripts to plant anatomy to species' effects on ecosystem processes. Typically, when functional traits are used in practice, the identity of the species is replaced with a value derived from individual traits to predict how different species as well as ecosystems with different community compositions respond to environmental changes. For example, the amount of investment in a given unit of leaf area for different species might be used to predict how species change in abundance in response to drought or during succession (Ackerly, 2004; Shipley et al., 2006; Wright et al., 2010).

Given the diversity of plant functional traits to study, a long-standing question is which functional traits of species are diagnostic, if not directly responsible for a species' success or failure in a given environment? As we detail here, quantification of plant tolerances to low resource availability is advancing our understanding of the dynamics of ecosystems and communities. Focusing on low resource tolerance allows classification of species based on traits that determine how species respond to the extreme conditions that are likely to cause differential mortality among species. Studies of low resource tolerances anchor a direct mechanistic understanding of species' ecological dynamics and generate predictive power to differentiate performance of plants across a range of environments, leading to a better understanding of ecological processes in an anthropogenic world. These tolerances then become the basis for ecological classification of species and the scaffolding to array more distal traits such as photosynthetic rates or xylem characteristics.

\section{APPROACHES TO CLASSIFICATION}

Over the past quarter century, research on plant functional traits has largely focused on the structure and function of individual organs - mainly leaves and stems, to a lesser degree roots (Craine et al., 2001; Wright et al., 2004; Chave et al., 2006). Such research has often quantified spectra of individual traits across species and environments and then tested for correlations among traits to generate multivariate trait associations. Trait correlations are interpreted in many instances to represent selection for a coordinated set of traits that collectively generate success under a given set of environmental conditions.

Despite some impressive global patterns and their necessary mechanistic role in plant performance (Wright et al., 2004), organlevel and ecophysiological traits suffer limitations as the basis of an ecological classification of plants. The functional traits usually considered in explaining patterns are relatively distal to the ecological performance of species, and the factors shaping 
phenotypes are complex (Houle et al., 2010). Natural selection can generate similar trait combinations between different resource environments as well as alternative trait combinations for a given environment (Marks and Lechowicz, 2006), limiting the application of these distal traits to predict differential performance across environments (Cunningham et al., 1999). Additionally, many organ- and sub-organ-level plant traits are highly plastic, and therefore are not consistently diagnostic of a species' ecological niche or potential performance (Craine and Reich, 2001; Craine et al., 2003). Consequently, classifications of species based on organ-level functional traits often have little predictive power for species performance and responses to environmental conditions (Russo et al., 2010; Wright et al., 2010).

An alternative approach is to classify species based on the performance of the plant as a whole under conditions that are likely to cause mortality. Measurements of whole-plant tolerances of low resource availability hold potential for representing the ecological performance of species. Low resource tolerances for species are determined by generating species' ecological response curves quantifying their performance across gradients of resource availability (Figure 2; Poorter et al., 2010). Generating these response curves allows plants to be classified by their tolerances for low resource availability or minimum requirements for different resources.

Low resource tolerances that are inferred from the abundance of species along resource gradients represent differences in species' realized niche (Smart et al., 2003; Humbert et al., 2007). For example, tolerance of low light levels can be inferred from the shadiest environments species are found. Although a rich source of information, using distributions of species to infer low resource tolerances is constrained by confounded resource gradients resources rarely vary independently of other environmental factors. In addition, these environmental indicator values cannot distinguish different evolutionary strategies to a common stress cacti and annual plants can be found adjacent to one another in deserts. Neither can environmental indicators be used to compare species across regions with non-overlapping species sets.

In complement to gradient analyses, experiments can be used to generate relationships between resource availability and performance in order to isolate responses of species to variation in individual resources. Resultant curves index the lowest resource availability at which plants can persist under a given set of conditions - the driest soils, the deepest shade, and the lowest supplies of nutrients (Figure 2). There are caveats to this approach too (see below), but the experimental approach generates unique explanatory power regarding community composition and ecosystem function and has great potential for broad syntheses. In the next three sections, we highlight particular examples of how understanding the tolerances of plants to drought, shade, and nutrient scarcity have improved our understanding of the structuring of communities and functioning of ecosystems.

\section{ENDURING THE DRY: DROUGHT TOLERANCE FROM ARID TO HUMID ECOSYSTEMS}

The intensity and frequency of drought - a period of low soil water availability - influence plant distributions, biodiversity, and ecosystem productivity globally (Zhao and Running, 2010). For many regions of the world, changes in the amount and variability of precipitation, combined with increasing temperature, and elevated atmospheric $\mathrm{CO}_{2}$ are altering the importance of drought (Knapp et al., 2008; Zhao and Running, 2010; McDowell et al., 2011; Romm, 2011; Jactel et al., 2012). Understanding how drought differentially affects plant species, and how that translates into plant performance, species distribution and ecosystem function is a pressing issue for advancing our comprehension of ecosystems and for projecting consequences of global change.

Drought creates physical stress for actively growing plants by generating tension within a plant's vascular system. The stress is measured as the plant's water potential with lower values representing greater stresses. The drought-induced tension itself is not necessarily fatal, but can lead to tension-induced cavitation and thus disruption of the transpiration stream in the xylem. That in turn can lead to desiccation of leaves, which few species can withstand. The long evolutionary history of plants under drought has generated a range of physiological ability to withstand the low plant water potentials that accompany drought.

The transient nature of drought increases the importance of avoiding temporary low water potentials by, for example, producing deep roots to tap stable water pools, senescing, or hydraulically isolating from the environment as occurs in succulents and isohydric species that rely on stored carbon until soils wet again (Pratt et al., 2008). Although plants have a number of strategies to avoid low plant water potentials, physiological drought tolerance is assessed as the lowest plant water potential at which a species can maintain key ecological functions, such as photosynthesis or turgor. Although plant water potentials have long been measured, the ability of plants to tolerate low internal water potentials has only recently been used as a diagnostic functional trait to characterize a species, which can then be used to explain ecological patterns.

To assess physiological drought tolerance, plant water potentials and performance metrics such as photosynthesis, stomatal conductance, wilting status, or hydraulic conductivity are monitored on plants in drying soils until a critical performance threshold is reached (Kursar et al., 2009; Tucker et al., 2011; Craine et al., 2012). The water potential at the performance threshold is then used as an index of physiological drought tolerance. This straightforward approach to generating a metric of physiological drought tolerance is currently behind a range of recent advances in our understanding of the role of drought in shaping ecological patterns and ecosystem functions worldwide.

Recently, physiological drought tolerance has been shown to be an important predictor of differences in survival among species in both arid and humid ecosystems. In Mediterranean-type climates, which typically have rain-free summers of variable length and intensity, physiologically drought tolerant woody chaparral species are better able to survive intense summer droughts than those species that are less tolerant of low water potentials (Pratt et al., 2008). In western North America, moderate drought can kill large stands of the relatively drought intolerant Populus tremuloides when plant water potentials fall sufficiently to cause widespread hydraulic failure (Anderegg et al., 2012). In contrast, Juniperus monosperma forests in the same regions of western North America do not experience wide-spread mortality from hydraulic failure 


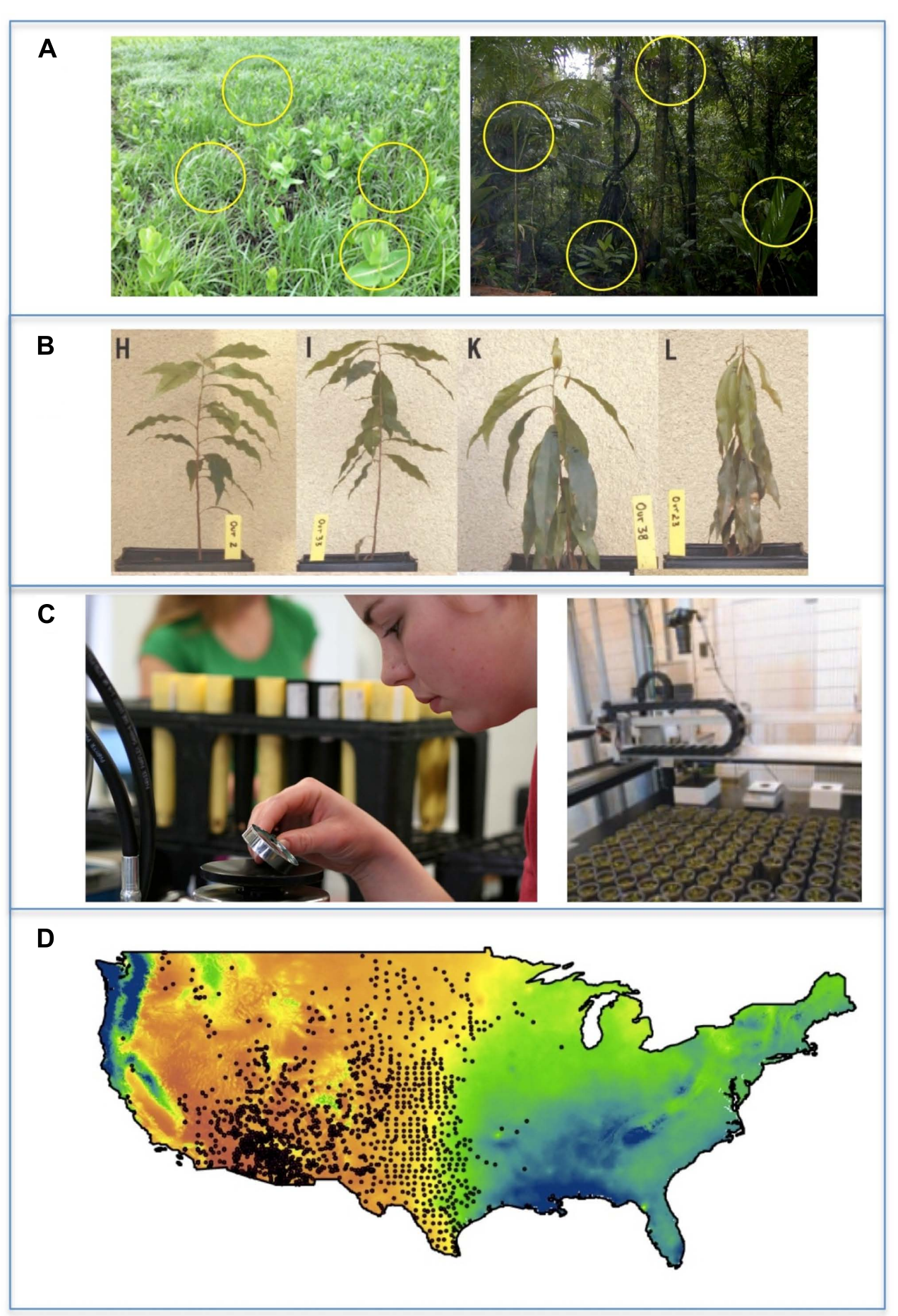

FIGURE 2 | A general overview of the stages of screening species' low resource tolerance traits for species. (A) All screening efforts begin with species selection. Species are often selected to vary in abundance or in their responses to environmental factors. Species may be selected to represent phylogenetically different lineages or invasiveness. (B) Focal species are grown or sampled under natural or experimental gradients of resource availability. For example, to quantify physiological drought tolerance of tropical trees, plant water potentials were monitored on drying plants until wilting (Engelbrecht etal., 2007). (C) Experiments usually require measuring plant growth, plant resource status, or resource exchange rates to determine the level at which growth or resource balance becomes neutral (see Figure 3). Automated measurements of growth are increasingly being adopted, but these are generally restricted to comparing different genotypes. (D) The ultimate goal of screening experiments is to relate interspecific differences in tolerance values obtained for drought, shade and low nutrients to differences among species in performance, abundance, or distributions, such as the distribution of the $\mathrm{C}_{4}$ grass Aristida purpurea in the US displayed over mean annual precipitation. In this stage, data may have to be reduced in dimensionality or phylogenetically weighted. Trait values are then substituted for species identity and the explanatory power of different traits tested. 
until much lower water potentials than Populus tremuloides (Breshears et al., 2009). Even at the wetter end of the climate spectrum, physiological drought tolerance can be important. Despite a mean annual precipitation of $2600 \mathrm{~mm}$, physiological drought tolerance still explained the extent of growth and survival reductions under drought for species in moist tropical forests of Central Panama (Kursar et al., 2009).

Differences in performance under drought conditions also control the geographic distributions of species across a wide variety of ecosystems, which suggests that drought can filter physiologically drought-intolerant species from drier areas, impacting patterns of diversity along aridity gradients. In Panamanian forests, experimentally assessed drought tolerance of tree seedlings explained the performance of naturally regenerated seedlings (Comita and Engelbrecht, 2009) and shaped local and regional distribution patterns across moisture gradients (Engelbrecht et al., 2007). Similarly, in Southeast Asian rain forests, tree species restricted to aseasonal forests were less physiologically drought tolerant than those species present in seasonally dry forests, despite greater precipitation in the seasonally dry forests than the aseasonal forests (2700 vs. $1950 \mathrm{~mm} \mathrm{year}^{-1}$; Baltzer et al., 2008). For 15 woody angiosperms from temperate forests in Tasmania, physiological drought tolerance correlated with how far into arid areas the species ranges extended (Blackman et al., 2012). Physiologically drought-tolerant tree species extend into forests with mean annual precipitation as low as $600 \mathrm{~mm}$, while physiologically droughtintolerant tree species are restricted to forests above $1000 \mathrm{~mm}$ mean annual precipitation.

The role of physiological drought tolerance in structuring plant communities and determining plant distributions extends from forests and shrub lands to grasslands. In a humid North American grassland (mean annual precipitation of $\sim 850 \mathrm{~mm}$ ), physiologically drought-tolerant grasses were relatively more abundant on shallow, drought-prone soils than on deeper, mesic soils where drought intolerant species predominated. Physiologically drought-tolerant grassland species present there also typically extend further into more arid regions of North America than physiologically drought-intolerant species (Tucker et al., 2011).

\section{SURVIVING THE DARK: SHADE TOLERANCE AND THE DISTRIBUTION AND ABUNDANCE OF SPECIES}

Shade is an inevitable consequence of plant growth and becomes the most intense when nutrients and water are abundant and disturbance rare (Valladares and Niinemets, 2008). Global changes in resource availability such as eutrophication and warming will alter the geographic distribution and intensity of shade, and hence the importance of shade as a driver in ecosystem dynamics. Under intact canopies on productive sites, as little as $0.5 \%$ of the sunlight reaches the ground (Coomes and Grubb, 2000), causing severe energy stress in shorter plants. Without repeated disturbances to limit leaf area, the development of shade drives changes in species composition and diversity by favoring species that can survive and grow under the lowered light levels, at least while beneath the canopy of others (Pacala and Tilman, 1994; Hautier et al., 2009; Fynn et al., 2011). The development of shade generally represents an increase in ecosystem carbon uptake since ecosystem leaf area is increasing, but also can restrict ecosystem carbon uptake by favoring species that are better at producing shade for competitive purposes than maximizing total photosynthesis (Anten, 2005).

Despite shade tolerance being one of the most common categorical classifications of forest trees (Swaine and Whitmore, 1988), the determinants of shade tolerance of species have been the subject of prolonged debate (Valladares and Niinemets, 2008). Points of contention have included the degree to which growth and survival in shade are coupled (Kobe et al., 1995; Baltzer and Thomas, 2007), the relative importance of functional traits that promote carbon gain versus those favoring carbon conservation (Givnish, 1988; Walters and Reich, 1999; Poorter and Kitajima, 2007), the role of ontogeny (Valladares and Niinemets, 2008), and how to measure the height of light reduction for purposes of assessing competition for light (Fahey et al., 1998). Although the ability to respond quickly to sunflecks has been posited as central to shade tolerance (Chazdon and Pearcy, 1991) this has not been supported by subsequent research (Naumburg and Ellsworth, 2000).

In a similar manner to physiological drought tolerance, shade tolerance can be assessed as the lowest light levels that plants can grow or survive for extended periods, i.e., the whole-plant light compensation point for growth (Baltzer and Thomas, 2007). The approach of measuring whole-plant shade tolerance recognizes the protracted nature of the struggle to survive under chronically low light levels, integrating a number of factors that are known to influence species differences in low-light carbon balance and the long time frames that it can take for shade to cause mortality. Shade-tolerant plants maintain positive carbon balance in low light by minimizing losses due to foliage turnover, herbivory and mechanical damage (Veneklaas and Poorter, 1998; Walters and Reich, 1999; Pauw et al., 2004; Kitajima and Poorter, 2010), and by having low respiration rates (Walters and Reich, 1999; Baltzer and Thomas, 2007). Like physiological drought tolerance, only recently has shade tolerance been adopted as a quantitative functional trait.

Direct measurements of shade tolerance have contributed to our understanding of species coexistence. Over 30 years ago, it was first hypothesized that a trade-off between shade tolerance and maximum growth rate could underlie tree species coexistence in old-growth forests (Denslow, 1980). Confirmation of this trade-off in several forest biomes has since established it as a central tenet of forest ecology (Hubbell and Foster, 1992; Kobe et al., 1995; Sánchez-Gómez et al., 2006; Sterck et al., 2006). Although chance undeniably contributes to species coexistence (Hubbell et al., 1999), the role of recruitment limitation in disrupting nichebased partitioning of understory light environments was initially overestimated because of sampling at inappropriate scales (Kobe and Vriesendorp, 2009). Quantifying the shade tolerance of species also contributes to our understanding of latitudinal diversity gradients. High sun angles result in more light reaching the forest floor beneath tree-fall gaps in the tropics than at higher latitudes, allowing coexistence of a broader diversity of light demand among species (Ricklefs, 1977; Loehle, 2000; Lusk et al., 2011).

Interspecific variation in shade tolerance contributes to how species sort across landscapes and regions. In a tropical rainforest, tree species associated with fertile valley bottoms were consistently more shade tolerant than congeners that were more common on 
less-fertile ridges (Baltzer and Thomas, 2007). Shade-intolerant Nothofagus species (Lusk et al., 2006) are ubiquitous in the Andes of south-central Chile where disturbances that generate high-light environments are prevalent but less common in nearby coastal ranges that lack frequent large-scale disturbances (Veblen et al., 1981). In general, global geographic patterns of shade and shade tolerance have yet to be evaluated. Although shade tolerance is expected to be most highly developed in high-productivity ecosystems with infrequent disturbance (Coomes and Grubb, 2000; Valladares and Niinemets, 2008), there have been no broad tests of this hypothesis.

An awareness of shade tolerance can also inform understanding and management of plant invasions. Acer platanoides invades forests in northeastern USA in part because it grows faster in high light than native trees of comparable shade tolerance (Martin et al., 2010). The invasive potential of shade-tolerant exotics in general may have been dangerously underestimated, their penetration of undisturbed vegetation going largely unrecognized because of the long time lag between seedling establishment and canopy recruitment (Martin et al., 2008).

\section{THRIVING IN THE BARREN: THE UNREALIZED POTENTIAL OF LOW NUTRIENT TOLERANCE}

Global change factors not only have the potential to alter drought and shade, but also the availability of nutrients such as nitrogen and phosphorus to plants (Figure 1). Though no synthesis has yet been generated, some terrestrial ecosystems have been becoming more eutrophic (Smart et al., 2003), while nutrient availability may have been declining over time in others (McLauchlan et al., 2010). These changes likely influence the relative importance of the tolerance of low nutrient availability (Figure 1), which would in turn alter community composition based on species' ability to perform under low nutrient availability. Although it has been hypothesized that nutrient scarcity selects for the same basic adaptations as drought and shade, scarcity of nutrients, whether abiotic in origin or driven primarily by competition, limits the growth of plants in ways that are fundamentally different than drought or shade. For example, nutrient scarcity does not generate the physical stresses of low water potentials, nor is it accompanied by a deficit of energy to the leaves.

Despite these fundamental differences with other stresses, there has been little direct quantification of minimum nutrient availability or supply requirements for different species that would index their tolerance of nutrient scarcity and lead to novel classification of species. In part, this can be explained by difficulties associated with measuring and manipulating nutrient supplies. The supplies of nutrients to plants grown under semi-natural conditions are not as easy to measure as plant water potentials or irradiance levels. Plants can both increase nutrient availability and promote the sequestration of nutrients by microbes, which makes experimental gradients of nutrient supplies difficult to maintain (Wedin and Tilman, 1990).

Although these factors make generating ecological response curves more difficult, a few studies have nevertheless generated ecological response curves by growing species under a range of nutrient supplies in hydroponics (Schortemeyer et al., 2002) or field experiments (Wedin and Tilman, 1993), such that minimum nutrient supplies required for growth can be estimated (Figure 3 ). Similar to studies that utilize indices of tolerance of low nutrient availability from distributions along environmental gradients to detect patterns of eutrophication (Smart et al., 2003), these studies have shown strong potential for a new ecological classification of species based on tolerance of low nutrient availability. Species' performance under low nutrient supply can predict their relative abundance when nutrients are scarce - plant species that sustain lower equilibrium soil inorganic $\mathrm{N}$ levels and higher root length density (Figure 3) are relatively more abundant when $\mathrm{N}$ is limiting (Fargione and Tilman, 2006).

That said, the story of our ecological understanding of plant performance under nutrient scarcity is mostly about what we have yet to learn. The number of experiments that quantify the ecological tolerance of plants to long periods of nutrient scarcity lags far behind those for drought and shade, which limits our understanding of whether minimum nutrient supply requirements are indicative of survival and competitive ability under low nutrient availability. The lack of data subsequently limits our ability to identify the functional traits that reliably differentiate species with respect to performance at low nutrient availability from low availability of other resources. For example, low tissue nutrient concentrations and high tissue longevity are almost universally considered key adaptations to low nutrient availability. Yet these traits are plastic enough such that under some experimental conditions species that predominate under low nutrient availability have higher foliar $\mathrm{N}$ concentrations and lower leaf longevity than species considered adapted to high nutrient availability (Craine and Reich, 2001).

\section{INTEGRATION AND FUTURE DIRECTIONS}

Evolution has produced over a quarter million seed-producing plant species in the world that are each unique in how they relate to their environments. As such, arraying the global flora onto just a few axes will never adequately represent the diversity of plant life. Yet, quantifying the tolerance of species to drought, shade, and nutrient scarcity has been advancing an ecological classification scheme that is critical to explaining the evolution, distribution, and diversity of terrestrial plant species as well as the functioning of future ecosystems where the availability of water, light, and nutrients are likely to be altered. Though understanding the ecology of species requires examining functional traits at a variety of scales from organs to genes, with respect to ecological classification, the proximal should precede the distal. Focusing on whole plants and quantifying low resource tolerances generates synergistic understanding of the ecology of plants that explains a number of ecological patterns and serves as the broader context for understanding variation in traits that are more distal to species performance.

Standardized protocols for measuring low resource tolerances are central to the ecological classification of plants. Currently, different studies use measurements of tolerance for a given resource that are similar, but non-comparable. In addition, growing conditions at the global scale are inherently different and the tolerances or requirements of different species can be non-overlapping. Hence, comparisons of drought tolerance or shade tolerance across biomes are difficult. Research communities need to agree on one 

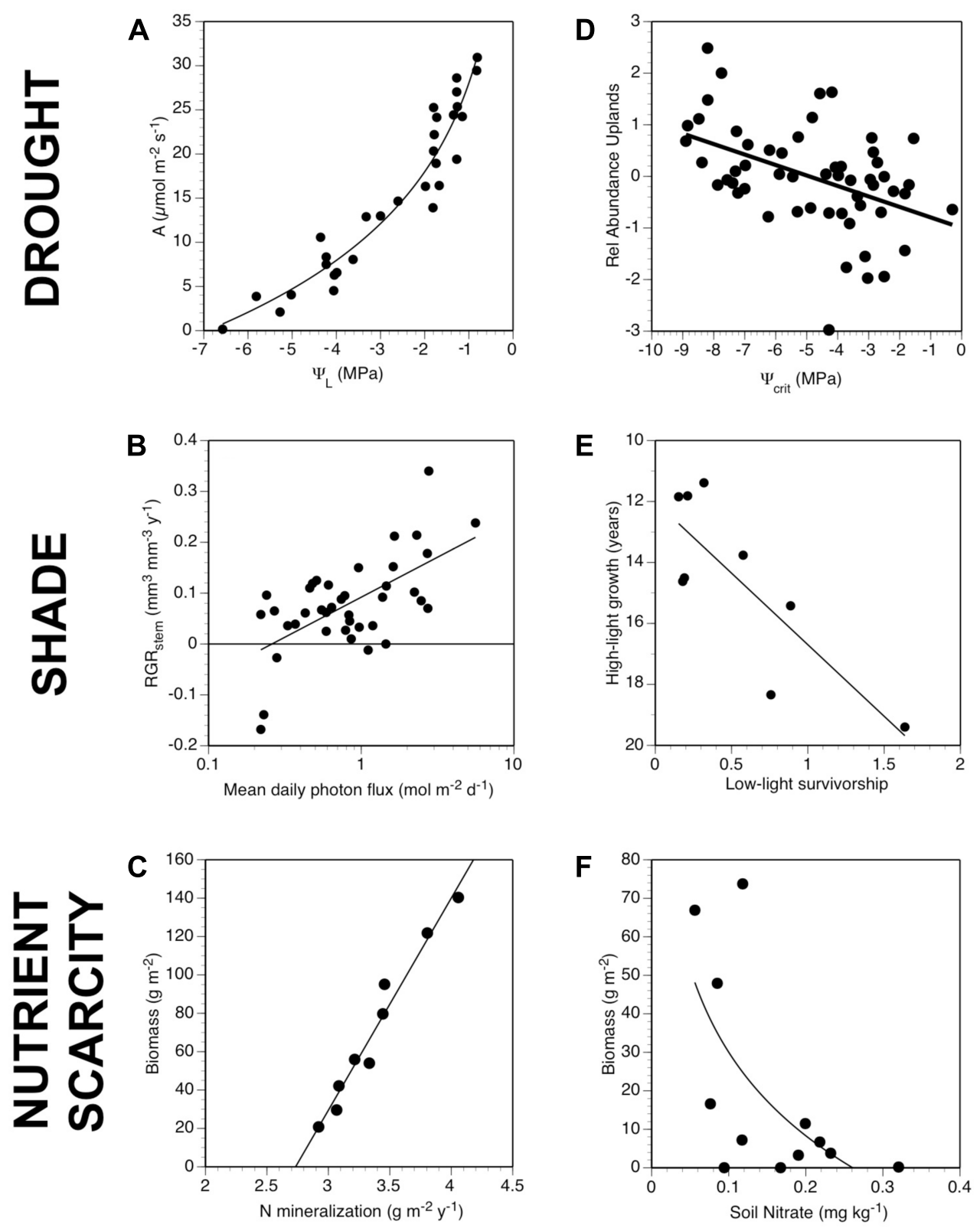

FIGURE 3 | Parallel patterns for drought, shade, and nutrient scarcity of generating and applying low resource tolerance traits. The first column (A-C) shows examples of response curves for water (photosynthetic rates vs. leaf water potential for a $\mathrm{C}_{4}$ grass; Baruch etal., 1985), light (relative growth rate of stems vs. irradiance for a temperate understory tree; Lusk, unpublished), and nutrient availability (growing season biomass vs. nitrogen mineralization rates for $\mathrm{a}_{3}$ grass across a gradient of soils with different soil organic matter levels; Wedin and Tilman, 1990; Wedin and Tilman, 1993). The second column (D-F) shows examples of relationships between low resource tolerance traits and differential performance of species: relative abundance of grassland species in drier uplands vs. wetter lowlands (difference in log-transformed cover; Tucker et al., 2011); tradeoffs in growth of temperate trees in high light (years to reach $3 \mathrm{~m}$ in height) vs. survivorship in low light conditions (Kobe etal., 1995), and relative abundance of species in experimental diversity plots vs. root length density of species grown in monoculture on soils with low nutrient availability (Fargione and Tilman, 2006). or two useful metrics of tolerance for each resource to facilitate arraying species grown under different conditions into common analyses.

Independently measuring tolerances to low availability of multiple resources will be critical for testing key evolutionary and ecological questions. For example, qualitative classifications of tree species suggest strong evolutionary or physiological trade-offs between drought and shade tolerance (Niinemets and Valladares, 2006). Yet, these results are based on subjective classifications rather than rigorous experimental testing. More than likely, given some of the complexity of measuring tolerances and the number of ancillary questions associated with the underlying determinants of tolerances, model sets of species need to be generated to facilitate integrated research by multiple investigators. 
Another key arena for progress is expanding the number of species that are measured. Typical ecological experiments measure tolerances of tens of species. Examining geographic or phylogenetic patterns of low resource tolerances will require coordinated experiments that measure species (and genotypes) on the scales of hundreds to thousands of species. As an example, many seed banks have multiple genotypes of tens of thousands of species and a single $40 \mathrm{~m}^{2}$ greenhouse could simultaneously grow every one of the approximately 11,000 extant grass species. In some cases, scaling experiments to more species can be done immediately, but the experimental approaches and bioinformatic techniques of other disciplines will likely eventually be useful for global ecological classifications of plants. Screening thousands of species can be enhanced with techniques that automate the handling and measurement of plants (Rascher et al., 2011). These techniques, first developed in commercial horticulture, are readily employed in research on Arabidopsis and crop species (Skirycz et al., 2011) to measure thousands of plants in individual experiments. When combined with ever-expanding databases of plant occurrence that are used to generate climate envelopes of species, low resource tolerance traits for a large number of species can then be applied

\section{REFERENCES}

Ackerly, D. (2004). Functional strategies of chaparral shrubs in relation to seasonal water deficit and disturbance. Ecol. Monogr. 74, 25-44.

Anderegg, W. R., Berry, J. A., Smith, D. D., Sperry, J. S., Anderegg, L. D., and Field, C. B. (2012). The roles of hydraulic and carbon stress in a widespread climate-induced forest die-off. Proc. Natl. Acad. Sci. U.S.A. 109, 233-237.

Anten, N. P. R. (2005). Optimal photosynthetic characteristics of individual plants in vegetation stands and implications for species coexistence. Ann. Bot. 95, 495-506.

Baltzer, J. L., Davies, S. J., Bunyavejchewin, S., and Noor, N. S. M. (2008). The role of desiccation tolerance in determining tree species distributions along the MalayThai Peninsula. Funct. Ecol. 22, 221-231.

Baltzer, J. L., and Thomas, S. C. (2007). Determinants of whole-plant light requirements in Bornean rain forest tree saplings. J. Ecol. 95, 1208-1221.

Baruch, Z., Ludlow, M. M., and Davis, R. (1985). Photosynthetic responses of native and introduced C4 grasses from Venezuelan savannas. Oecologia 67, 388-393.

Blackman, C. J., Brodribb, T. J., and Jordan, G. J. (2012). Leaf hydraulic vulnerability influences species' bioclimatic limits in a diverse group of woody angiosperms. Oecologia 168, $1-10$.

Breshears, D. D., Myers, O. B., Meyer, C. W., Barnes, F. J., Zou, C. B.,
Allen, C. D., et al. (2009). Tree dieoff in response to global change-type drought: mortality insights from a decade of plant water potential measurements. Front. Ecol. Environ. 7, 185-189.

Briggs, J. M., and Knapp, A. K. (1995). Interannual variability in primary production in tallgrass prairie: climate, soil moisture, topographic position, and fire as determinants of aboveground biomass. Am. J. Bot. 82, 1024-1030.

Chave, J., Muller-Landau, H. C., Baker, T. R., Easdale, T. A., Steege, H. T., and Webb, C. O. (2006). Regional and phylogenetic variation of wood density across 2456 neotropical tree species. Ecol. Appl. 16, 2356-2367.

Chazdon, R. L., and Pearcy, R. W. (1991). The importance of sunflecks for forest understory plants photosynthetic machinery appears adapted to brief, unpredictable periods of radiation. Bioscience 41, 760-766.

Comita, L. S., and Engelbrecht, B. M. J. (2009). Seasonal and spatial variation in water availability drive habitat associations in a tropical forest. Ecology 90, 2755-2765.

Coomes, D. A., and Grubb, P. J. (2000). Impacts of root competition in forests and woodlands: a theoretical framework and review of experiments. Ecol. Monogr. 70, 171-207.

Craine, J. (2009). Resource Strategies of Wild Plants. Princeton: Princeton University Press.

Craine, J. M., Froehle, J., Tilman, D. G., Wedin, D. A., and Chapin, F. S., and

to the global scale in order to parameterize models of ecosystem function (Poulter et al., 2011).

In all, we propose that coupling current efforts on understanding plant functional traits with whole-plant tolerances to drought, shade, and nutrient scarcity will continue to uncover many of the determinants of community composition and ecosystem function that have long lain hidden. Isolating the importance of these three resource stresses will also set into relief other factors that have shaped the evolution of plants and structure communities and ecosystems today. A predictive framework based on low resource tolerance will be key to understanding how plant communities and ecosystems will respond to the rash of changes that they face in the near future.

\section{ACKNOWLEDGMENTS}

Sabrina Russo, Lourens Poorter, Bill Lee, Jeff Dukes, Jennifer Baltzer, Lizzie Wolkovich, Peter Reich, and two anonymous reviewers all provided helpful discussion or comments. Christopher H. Lusk was supported by ARC Discovery grant DP1094606, Nate G. McDowell was supported by DOE Office of Science (BER), LANL-LDRD.

Iii. (2001). The relationships among root and leaf traits of 76 grassland species and relative abundance along fertility and disturbance gradients. Oikos 93, 274-285.

Craine, J. M., Ocheltree, T. W., Nippert, J. B., Towne, E. G., Skibbe, A. M., Kembel, S. W., et al. (2012). Global diversity of drought tolerance and grassland climate-change resilience. Nat. Clim. Change doi: 10.1038/nclimate1634 [Epub ahead of print].

Craine, J. M., and Reich, P. B. (2001). Elevated CO2 and nitrogen supply alter leaf longevity of grassland species. New Phytol. 150 397-493.

Craine, J. M., Wedin, D. A., Chapin, F. S. III, and Reich, P. B. (2003). Development of grassland root systems and their effects on ecosystem properties. Plant Soil 250, 39-47.

Cunningham, S. A., Summerhayes, B. and Westoby, M. (1999). Evolutionary divergences in leaf structure and chemistry, comparing rainfall and soil nutrient gradients. Ecol. Monogr 69, 569-588.

Denslow, J. S. (1980). Gap partitioning among tropical rainforest trees. Biotropica 12(Suppl.), 47-55.

Dermody, O., Long, S. P., and Delucia, E. H. (2006). How does elevated $\mathrm{CO} 2$ or ozone affect the leafarea index of soybean when applied independently? New Phytol. 169, 145-155.

Engelbrecht, B. M., Comita, L. S., Condit, R., Kursar, T. A., Tyree, M. T., Turner, B. L., et al. (2007). Drought sensitivity shapes species distribution patterns in tropical forests. Nature 447, 80-82.

Fahey, T. J., Battles, J. J., and Wilson, G. F. (1998). Responses of early successional northern hardwood forests to changes in nutrient availability. Ecol. Monogr. 68, 183-212.

Fargione, J., and Tilman, D. (2006). Plant species traits and capacity for resource reduction predict yield and abundance under competition in nitrogen-limited grassland. Funct. Ecol. 20, 533-540.

Field, C. B., Chapin, F. S., Matson, P. A., and Mooney, H. A. (1992). Responses of terrestrial ecosystems to the changing atmosphere: a resourcebased approach. Annu. Rev. Ecol. Syst. 23, 201-235.

Fynn, R., Morris, C., Ward, D., and Kirkman, K. (2011). Trait-environment relations for dominant grasses in South African mesic grassland support a general leaf economic model. J. Veg. Sci. 22, 528-540.

Givnish, T. J. (1988). Adaptation to sun and shade: a whole plant perspective. Aust. J. Plant Physiol. 15, 63-92.

Grime, J. P. (2001). Plant Strategies, Vegetation Processes, and Ecosystem Properties. Chichester: John Wiley \& Sons Ltd.

Hautier, Y., Niklaus, P. A., and Hector, A. (2009). Competition for light causes plant biodiversity loss after eutrophication. Science 324, 636-638.

Houle, D., Govindaraju, D. R., and Omholt, S. (2010). Phenomics: the next challenge. Nat. Rev. Genet. 11, 855-866.

Hubbell, S. P., and Foster, R. B. (1992). Short-term dynamics of a neotropical 
forest: Why ecological research matters to tropical conservation and management. Oikos 63, 48-61.

Hubbell, S. P., Foster, R. B., O’Brien, S. T., Harms, K. E., Condit, R., Wechsler, B., et al. (1999). Light-gap disturbances, recruitment limitation, and tree diversity in a neotropical forest. Science 283, 554-557.

Humbert, L., Gagnon, D., Kneeshaw, D., and Messier, C. (2007) A shade tolerance index for common understory species of northeastern North America. Ecol. Indic. 7, 195-207.

Jactel, H., Petit, J., Desprez-Loustau, M.L., Delzon, S., Piou, D., Battisti, A., et al. (2012). Drought effects on damage by forest insects and pathogens: a meta-analysis. Glob. Change Biol. 18, 267-276.

Kitajima, K., and Poorter, L. (2010). Tissue-level leaf toughness, but not lamina thickness, predicts sapling leaf lifespan and shade tolerance of tropical tree species. New Phytol. 186, 708-721.

Knapp, A. K., Beier, C., Briske, D. D., Classen, A. T., Luo, Y., Reichstein, M., et al. (2008). Consequences of more extreme precipitation regimes for terrestrial ecosystems. Bioscience 58, 811-821.

Knapp, A. K., and Smith, M. D. (2001). Variation among biomes in temporal dynamics of aboveground primary production. Science 291, 481-484.

Kobe, R. K., Pacala, S. W., Silander, J. A., and Canham, C. D. (1995). Juvenile tree survivorship as a component of shade tolerance. Ecol. Appl. 5, 317-332.

Kobe, R. K., and Vriesendorp, C. F. (2009). Size of sampling unit strongly influences detection of seedling limitation in a wet tropical forest. Ecol. Lett. 12, 220-228.

Koch, O., Tscherko, D., and Kandeler, E. (2007). Temperature sensitivity of microbial respiration, nitrogen mineralization, and potential soil enzyme activities in organic alpine soils. Glob. Biogeochem. Cycles 21, GB4017.

Kursar, T. A., Engelbrecht, B. M. J., Burke, A., Tyree, M. T., Ei Omari, B., and Giraldo, J. P. (2009). Tolerance to low leaf water status of tropical tree seedlings is related to drought performance and distribution. Funct. Ecol. 23, 93-102.

Loehle, C. (2000). Strategy space and the disturbance spectrum: A lifehistory model for tree species coexistence. Am. Nat. 156, 14-33.

Lusk, C. H., Chazdon, R. L., and Hofmann, G. (2006). A bounded null model explains juvenile tree community structure along light availability gradients in a temperate rain forest. Oikos 112, 131-137.

Lusk, C. H., Kooyman, R., and Sendall, K. (2011). Latitude, solar elevation angles and gap-regenerating rain forest pioneers. J. Ecol. 99, 491-502.

Marks, C. O., and Lechowicz, M. J. (2006). Alternative designs and the evolution of functional diversity. Am. Nat. 167, 55-66.

Martin, P. H., Canham, C. D., and Kobe, R. K. (2010). Divergence from the growth-survival trade-off and extreme high growth rates drive patterns of exotic tree invasions in closed-canopy forests. J. Ecol. 98, 778-789.

Martin, P. H., Canham, C. D., and Marks, P. L. (2008). Why forests appear resistant to exotic plant invasions: intentional introductions, stand dynamics, and the role of shade tolerance. Front. Ecol. Environ. 7, 142-149.

McDowell, N. G., Beerling, D. J., Breshears, D. D., Fisher, R. A., Raffa, K. F., and Stitt, M. (2011). The interdependence of mechanisms underlying climate-driven vegetation mortality. Trends Ecol. Evol. 26, 523-532.

McLauchlan, K. K., Ferguson, C. J., Wilson, I. E., Ocheltree, T. W., and Craine, J. M. (2010). Thirteen decades of foliar isotopes indicate declining nitrogen availability in central North American grasslands. New Phytol. 187, 1135-1145.

Naumburg, E., and Ellsworth, D. S. (2000). Photosynthetic sunfleck utilization potential of understory saplings growing under elevated $\mathrm{CO} 2$ in FACE. Oecologia 122, 163-174.

Niinemets, U., and Valladares, F. (2006). Tolerance to shade, drought, and waterlogging of temperate Northern Hemisphere trees and shrubs. Ecol. Monogr. 76, 521-547.

Pacala, S. W., and Tilman, D. (1994). Limiting similarity in mechanistic and spatial models of plant competition in heterogeneous environments. Am. Nat. 143, 222-257.

Pauw, A., Van Bael, S. A., Peters, H. A., Allison, S. D., Camargo, J. L. C., Cifuentes-Jara, M., et al. (2004). Physical damage in relation to carbon allocation strategies of tropical forest tree saplings. Biotropica 36, 410-413.

Poorter, H., Niinemets, U., Walter, A., Fiorani, F., and Schurr, U. (2010). A method to construct doseresponse curves for a wide range of environmental factors and plant traits by means of a meta-analysis of phenotypic data. J. Exp. Bot. 61, 2043-2055.

Poorter, L., and Kitajima, K. (2007). Carbohydrate storage and light requirements of tropical moist and dry forest tree species. Ecology 88, 1000-1011.

Poulter, B., Ciais, P., Hodson, E., Lischke, H., Maignan, F., Plummer, S., et al. (2011). Plant functional type mapping for earth system models. Geosci. Model Dev. 4, 993-1010.

Pratt, R. B., Jacobsen, A. L., Mohla, R., Ewers, F. W., and Davis, S. D. (2008). Linkage between water stress tolerance and life history type in seedlings of nine chaparral species (Rhamnaceae). J. Ecol. 96, 1252-1265.

Rascher, U., Blossfeld, S., Fiorani, F., Jahnke, S., Jansen, M., Kuhn, A. J., etal. (2011). Noninvasive approaches for phenotyping of enhanced performance traits in bean. Funct. Plant Biol. 38, 968-983.

Ricklefs, R. E. (1977). Environmental heterogeneity and plant species diversity: a hypothesis. Am. Nat. 111, 376-381.

Rind, D., Goldberg, R., Hansen, J., Rosenzweig, C., and Ruedy, R. (1990). Potential evapotranspiration and the likelihood of future drought. J. Geophys. Res. 95, 9983-10004.

Romm, J. (2011). The next dust bowl. Nature 478, 450-451.

Russo, S. E., Cannon, W. L., Elowsky, C., Tan, S., and Davies, S. J. (2010) Variation in leaf stomatal traits of 28 tree species in relation to gas exchange along an edaphic gradient in a Bornean rain forest. Am. J. Bot. 97, 1109-1120.

Sánchez-Gómez, D., Valladares, F., and Zavala, M. A. (2006). Performance of seedlings of Mediterranean woody species under experimental gradients of irradiance and water availability: trade-offs and evidence for niche differentiation. New Phytol. 170, 795-806.

Schortemeyer, M., Atkin, O. K., Mcfarlane, N., and Evans, J. R. (2002). N-2 fixation by Acacia species increases under elevated atmospheric CO2. Plant Cell Environ. 25, 567-579.

Searles, P. S., Flint, S. D., and Caldwell, M. M. (2001). A meta analysis of plant field studies simulating stratospheric ozone depletion. Oecologia 127, 1-10.

Shipley, B., Vile, D., and Garnier, E. (2006). From plant traits to plant communities: a statistical mechanistic approach to biodiversity. Science $314,812-814$
Skirycz, A., Vandenbroucke, K., Clauw, P., Maleux, K., De Meyer, B., Dhondt, S., et al. (2011). Survival and growth of Arabidopsis plants given limited water are not equal. Nat. Biotechnol. 29, 212-214.

Smart, S. M., Robertson, J. C., Shield, E. J., and Van De Poll, H. M. (2003). Locating eutrophication effects across British vegetation between 1990 and 1998. Glob. Change Biol. 9, 1763-1774.

Stanford, G., and Epstein, E. (1974). Nitrogen mineralization-water relations in soils. Soil Sci. Soc. Am. J. 38, 103-107.

Sterck, F. J., Poorter, L., and Schieving, F. (2006). Leaf traits determine the growth-survival trade-off across rain forest tree species. Am. Nat. 167, 758-765.

Swaine, M. D., and Whitmore, T. C. (1988). On the definition of ecological species groups in tropical rain forests. Vegetation 75, 81-86.

Tilman, D. (1988). Plant Strategies and the Dynamics and Function of Plant Communities. Princeton: Princeton University Press.

Tucker, S. S., Craine, J. M., and Nippert, J. B. (2011). Physiological drought tolerance and the structuring of tallgrass assemblages. Ecosphere 2, 48.

Valladares, F., and Niinemets, U. (2008). Shade tolerance, a key plant feature of complex nature and consequences. Annu. Rev. Ecol. Evol. Syst. 39, 237-257.

Veblen, T. T., Donoso, C., Schlegel, F. M., and Escobar, B. R. (1981). Forest dynamics in south-central Chile. J. Biogeography 8, 211-247.

Veneklaas, E. J., and Poorter, L. (1998). "Growth and carbon partitioning of tropical tree seedlings in contrasting light environments," in Inherent Variation in Plant Growth: Physiological Mechanisms and Ecological Consequences, eds H. Lambers, H. Poorter, and M. M. I. Van Vuuren (Leiden: Backhuys), 337-362.

Walters, M. B., and Reich, P. B. (1999). Low-light carbon balance and shade tolerance in the seedlings of woody plants: do winter deciduous and broad-leaved evergreen species differ? New Phytol. 143, 143-154.

Warming, E. (1909). The Oecology of Plants. Oxford: Clarendon Press.

Wedin, D. A., and Tilman, D. (1990). Species effects on nitrogen cycling: a test with perennial grasses. Oecologia 84, 433-441.

Wedin, D. A., and Tilman, D. G. (1993). Competition among grasses along a nitrogen gradient: Initial conditions and mechanisms of 
competition. Ecol. Monogr. 63, 199-229.

Wilson, S. D., and Tilman, D. (1993). Plant competition and resource availability in response to disturbance and fertilization. Ecology 74, 599-611.

Wright, I. J., Reich, P. B., Westoby, M., Ackerly, D. D., Baruch, Z., Bongers, F., et al. (2004). The worldwide leaf economics spectrum. Nature 428, 821-827.

Wright, S. J., Kitajima, K., Kraft, N. J. B., Reich, P. B., Wright, I. J., Bunker,
D. E., et al. (2010). Functional traits and the growth-mortality trade-off in tropical trees. Ecology 91, 3664-3674. Zhao, M., and Running, S. W. (2010). Drought-induced reduction in global terrestrial net primary production from 2000 through 2009. Science 329, 940-943.

Conflict of Interest Statement: The authors declare that the research was conducted in the absence of any commercial or financial relationships that could be construed as a potential conflict of interest.

Received: 26 August 2012; accepted: 15 October 2012; published online: 30 October 2012.

Citation: Craine JM, Engelbrecht BMJ, Lusk $\mathrm{CH}$, McDowell NG and Poorter $H$ (2012) Resource limitation, tolerance, and the future of ecological plant classification. Front. Plant Sci. 3:246. doi: 10.3389/fpls.2012.00246
This article was submitted to Frontiers in Functional Plant Ecology, a specialty of Frontiers in Plant Science.

Copyright (c) 2012 Craine, Engelbrecht, Lusk, McDowell and Poorter. This is an open-access article distributed under the terms of the Creative Commons Attribution License, which permits use, distribution and reproduction in other forums, provided the original authors and source are credited and subject to any copyright notices concerning any thirdparty graphics etc. 